\title{
SIMIENTE DE LOBO: CELAN, ADORNO Y LA POESÍA DESPUÉS DE AUSCHWITZ ${ }^{1}$
}

Ricardo IBA RLUCÍA ${ }^{2}$

- RESUM EN: A partir de un poema póstumo de Paul Celan, el presente artículo analiza el dictum de Theodor W. A dorno sobre la imposibilidad de la lírica después de Auschwitz y busca determinar el impacto de tal proposición en la obra de Celan. Al mismo tiempo, indaga la recepción de la poesía de Celan en las ideas mismas de Adorno, particularmente en Negative Dialektik y Ästhetische Theorie. Por último, explora las paradojas de cualquier lenguaje poético que pretenda dar cuenta del Holocausto artísticamente.

- PALABRAS- CLAVES: Celan; Adorno; Auschwitz; poesía; lenguaje; arte.

\section{A Leiser Madanes}

El volumen Gedichte aus dem Nachlass, publicado en Alemania en 1997, reúne más de doscientos poemas excluidos por Paul Celan de los siete libros que proyectó en vida. Ninguno de estos poemas fue incluido posteriormente en las dos obras aparecidas después de su suicidio en

1 Enfoques parciales del tema fueron presentados en el IX Congreso Nacional de Filosofía organizado por AFRA (A sociación Filosófica Argentina) en la ciudad de La Plata, Provincia de Buenos Aires, el 30, 31 de octubre de 1997, y en el I Congreso Internacional "Razones de la crítica, celebrado en la Facultad de Humanidades y Artes de la UNR (Universidad Nacional de Rosario), el 14, 15 y 16 de octubre de 1998.

2 Departamentos de Filosofía de la UBA (Universidad de Buenos Aires) y la UNLP (Universidad Nacional de La Plata). Investigador asociado del CIF (Centro de Investigaciones Filosóficas). 
París en la primavera de 1970, ni en la edición en cinco tomos de su Gesammelte Werke (1983), preparada por Beda Alleman y Stefan Reichert, ni desde luego en las páginas de Das Frühwerk (1989). Aun cuando la totalidad del material contenido en este volumen constituye un aporte decisivo para el estudio de Celan, cuya poesía ha merecido en las últimas décadas un creciente interés filosófico, sobre todo a partir de los trabajos de Otto Pöggeler, Hans-Georg Gadamer, Emmanuel Levinas y J acques Derrida, deseo llamar aquí la atención sobre un poema en particular. Me refiero a "Wolfsbohne" ("Simiente de lobo"), uno de los textos que Celan decidió descartar de Die Niemandsrose en 1963. Entiendo que el asunto mismo del poema permite esbozar algunos comentarios sobre una cuestión que sin duda lo obsesionaba: el problema de la imposibilidad, según el dictum de Theodor W. A dorno, de escribir poesía después de Auschwitz.

Esta es la versión íntegra del poema en alemán y en mi traducción al español:

Wolfsbohne

... 0

Ihr Blüten von Deustchland, o mein

Herz wird

Untrügbarer Kristall, am dem

Das Licht sich prüfet, wenn Deutschland

Hölderlin, "Von A bgrund nämlich..."

... wie an den Häusern der Juden (zum Andenken des ruiniten J erusalem's), immer etwas unvollendet gelasse werden muss...

J ean-Paul, Das Kampaner Tal

Leg den Riegel vor: Es

sind Rosen im Haus.

Es sind

sieben Rosen im Haus.

Es ist

der Siebenleuchter im Haus.

Unser

Kind

weiss es und schläft.
Simiente de lobo

... oh

Flores de Alemania, oh mi corazón se vuelve

Un cristal que no puede engañar, en el cual

La luz examina, si Alemania

Hölderlin, "Cerca del abismo... "

... como en las casas de los judíos (para recordar las ruinas de Jerusalén) siempre algo debe ser dejado inconcluso..

J ean-Paul, El valle de Campania

Echa el cerrojo: Están

las rosas en casa.

Están

las siete rosas en la casa.

Está

el candelabro de siete brazos en casa.

Nuestro

hijo

lo sabe y duerme. 
(Welt, in Michailowka, in

der Ukraine, wo

sie mir Vater und Mutter erschlu-

gen: was

blühte dort, was

blüht dort? Welche

Blume, Mutter

tat dir dort weh

mit ihrem Namen?

Mutter, dir

die du Wolfsbohne sagtest, nicht:

Lupine.

Gestern
kam einer von ihnen und
tötete dich
zum andern Mal in
meinem Gedicht.
Mutter,
Mutter, wessen
Hand hab ich gedrückt,
da ich mit deinen
Worten ging nach
Deutschland?

In Aussig, sagtest du immer, in Aussig an

der Elbe,

auf der Flucht.

Mutter, es wohnten dort

Mörder.

Mutter, ich habe

Briefe geschrieben.

Mutter, es kam keine Antwort.

Mutter, es kam eine Antwort.

Mutter, ich habe

Briefe geschrieben an -

Mutter, sie schreiben Gedichte.

Mutter, sie schreiben sie nicht,

wär das Gedicht nicht, das

ich geschrieben hab, um

deinetwillen, um

deines
(Lejos, en Michailovka, en

Ucrania, donde

ellos asesinaron a mi padre y a mi

madre: ¿qué

florecía allí, qué

florece allí? ¿Cuál

flor, madre,

te hirió allí

con su nombre?

Tú, madre, que dijiste simiente de lobo, no: lupino.

Ayer uno de ellos vino y

te mató

de nuevo en

mi poema.

Madre,

madre, ¿de quién

era la mano que apreté

cuando con tus

palabras fui a

Alemania?

En Aussig, decías siempre, en Aussig a orillas

del Elba,

en la huida.

Madre, allí viven

asesinos.

Madre, yo

escribí cartas.

Madre, no tuve respuesta.

Madre, tuve una respuesta.

Madre, yo

escribí cartas a -

Madre, ellos escriben poemas.

Madre, ellos no los escribirían,

si no fuera por el poema que

yo escribí por

tu voluntad, por

voluntad 
Gottes

willen.

Gelobt, sprachst du, sei

der Ewige und

gepriesen, drei-

mal

Amen.

Mutter, sie schweigen.

M utter, sie dulden es, dass

die Niedertracht mich verleumdet.

Mutter, keiner

fällt den Mördern ins Wort.

M utter, sie schreiben Gedichte.

0

M utter, wieviel

fremdester Acker trägts deine

Frucht!

Trägt sie und nährt

die da töten!

M utter, ich

bin verloren.

M utter, wir

sind verloren.

M utter, mein Kind, das

dir ähnlich sieht.)

Leg den Riegel vor: Es

sind Rosen im Haus.

Es sind

sieben Rosen im Haus.

Es ist

der Siebenleuchter im Haus.

Unser

Kind

weiss es und schläft. de tu

Dios.

Loado, decías, sea

el Eterno y

agradecido, tres

veces

A mén.

Madre, ellos callan.

Madre, ellos toleran que

la vileza me calumnie.

Madre, nadie

corta a los asesinos la palabra.

Madre, ellos escriben poemas.

Oh

Madre, iqué

suelo más extraño produce tu fru-

to!

¡Lo produce y alimenta

a los que matan!

Madre, estoy

perdido.

Madre, estamos

perdidos.

Madre, mi hijo, que

se parece $a$ ti.)

Echa el cerrojo: Están

las rosas en casa.

Están

las siete rosas en casa.

Está

el candelabro de siete brazos en casa.

Nuestro

hijo

lo sabe y duerme.

(Celan, 1997a, p.45-8)

(Celan, 1997b, p.40) 
El original mecanografiado de "Wolfsbohne" se encuentra fechado el 21 de octubre de 1959. Titulado inicialmente "M enorah" y concebido, en palabras de Celan, como un "ejercicio contrapuntístico" a su memorable "Todesfuge", estaba destinado al Fischer-Almanach, pero a último momento decidió retirarlo, alegando que, "si bien Klaus Demus sostiene que ningún poema debe permanecer en el ámbito privado ... este poema debe quedar completamente en los límites de lo privado y ser sacado de circulación" (Celan, 1997a, p.359). Hasta abril de 1963, sin embargo, Celan todavía pensaba incluir "Wolfsbohne" en Die Niemandsrose, específicamente entre los poemas "Bei Wein und Verlorenheit" y "Zürich, Zum Storchen". ¿Cuál fue la razón que lo llevó a excluirlo de este libro y a no incluirlo tampoco en A temwende (1967), Fadensonnen (1968) y Lichtzwang (1970), sus libros siguientes? Michael Hamburger, el más destacado traductor de Celan al inglés, al presentar el poema a los lectores del Times Literary Supplement, conjeturó que "Wolfsbohne" debía resultar impublicable para Celan porque, "más descarnadamente que ninguno de sus otros poemas de madurez, exponía la herida de la muerte de sus padres en los campos de concentración." Según Hamburger, "mientras Celan creyó o confió en que esta herida podía curarse - incluso después de la muerte a poco de nacer de su primer hijo, François - el poema fue publicable; y algunas líneas añadidas tardíamente en 1965, que contradicen el 'Estoy perdido, estamos perdidos' de la versión de 1959 ... fueron un último y vano intento por no tratarlo como un poema, sino por orientarlo hacia la curación de esa herida" (Hamburger, 1997, p.26).

Hamburger alude, sin la menor duda, a un borrador de 1965 - incluido también en Gedichte aus dem Nachlass - en el que Celan agregó, tras la repetición de la estrofa de las "siete rosas", los siguientes versos finales:

$\begin{array}{ll}\text { Mutter, Unverlorene, mit uns, } & \text { Madre, lo no perdido, con nosotros, } \\ \text { den Unverlorenen, } & \text { los no perdidos, } \\ \text { siegst du. } & \text { venciste. } \\ \text { Und mit uns Wahr und Gerecht und } & \text { Y con nosotros lo verdadero y lo justo } \\ \text { Gerade, } & \text { y lo recto, } \\ \text { um } & \text { por } \\ \text { der versöhnenden } & \text { voluntad del } \\ \text { Liebe } & \text { amor } \\ \text { Willen. } & \text { que reconcilia. }\end{array}$

(Celan, 1997a, p.309) 
"Wolfsbohne" presenta algunas importantes referencias autobiog ráficas que es necesario tener en cuenta. En junio de 1955, dos años después de la muerte del pequeño François, Celan y Gisèle Lestrange tuvieron un segundo hijo, a quien Ilamaron Eric en homenaje a Friederika, la madre de Celan. Las "siete rosas", con las que se abre y se cierra la versión de 1959, aparecen también mencionadas en su temprano poema "Kristall" de Mohn und Gedächtnis (1952) y luego dando título - "Sieben Rosen später" ("Siete rosas más tarde") - a la primera parte de Von Schwelle zu Schwelle (1955), su segundo libro de poemas (Celan, 1983a, p.52 y 83). Michailovka es el lugar de Ucrania en que los padres de Celan fueron asesinados y Aussig, el nombre de un pueblo al norte de Bohemia donde su madre, una de las tantas judías rumanas del Imperio Austro-Húngaro, pasó durante su juventud un par de años huyendo de los pogromos. En cuanto a la expresión "Wolfsbohne", cabe decir que se trata de una composita acuñada por Celan, que pretende traducir literalmente la palabra de origen latino "Lupine", que como adjetivo designa una cualidad relativa al lobo (lupus en latín, Wolf en alemán) y como sustantivo, una planta herbácea (el altramuz), cuyo fruto desecado (el lúpulo) se usa para dar sabor amargo a la cerveza. No deja de ser significativo, en el contexto de este poema, que el cuartel general de Hitler en Polonia durante la Segunda Guerra se llamase "Wolfschanze", esto es, "Trinchera del lobo".

La redacción de "Wolfsbohne" coincide temporalmente con dos prosas claves de Celan: "Gespräch im Gebirg", el único texto de ficción escrito por Celan, y "Der Meridian", conferencia que pronunció en Darmstadt en 1960, al recibir el Premio Büchner, el galardón más importante de las letras germanas. Si puede decirse que "Der Meridian" constituye una defensa de la poesía después de Auschwitz bajo la forma de un discurso de agradecimiento a la Academia de la Lengua y la Literatura Alemana, "Gespräch im Gebirg" da cuenta de su desencuentro con Adorno en Sils-Maria, en los Alpes Suizos. En julio de 1959, "iba a encontrarme en Sils-Maria con el profesor Adorno, que pensaba que era judío", anotó entonces - como recuerda J ohn Felstiner, en su monumental biografía de Celan (Felstiner, 1995, p.139) - aludiendo tal vez al hecho de que Theodor Wiesengrund había suprimido el apellido judío de su padre y adoptado el de su madre, de origen católico. La entrevista, que había sido arreglada por Peter Szondi, amigo de Celan y uno de los primeros estudiosos de su obra, nunca llegó a concretarse, ya que Celan regresó antes de lo previsto a París, convencido de haberse desencontrado con Adorno "no por accidente" (Pöggeler, 1980, p.238). Poco después, en agosto de ese mismo año, Celan escribió "Gespräch 
im Gebirg", donde el judío "Klein" (Chico) dialoga en lo alto de una montaña con el judío "Groß" (Grande), "su pariente y su primo, un cuarto de vida de judío más viejo":

Un atardecer en el que el sol, y no sólo él, se había hundido en el ocaso, iba andando, dejó atrás su casita y allá iba andando el judío, y con él iba su nombre impronunciable, iba y venía, venía con paso lento, haciéndose oír, venía con su bastón, venía pisando la piedra, no me oyes, no me oyes, soy yo, yo, yo y aquel a quien oyes, a quien crees oír, yo y el otro - así iba, podía oírselo, iba un atardecer en que algo se había hundido en el crepúsculo, iba bajo las nubes, iba por la sombra, la propia y la ajena - pues el judío, lo sabes, qué tiene ahora el judío que realmente le pertenezca, que no sea tomado en préstamo, dado en préstamo y no devuelto -, así iba y venía, venía andando por el camino, que es lindo, incomparable, iba, como Lenz por las montañas, él, a quien habían hecho vivir allá abajo, allá donde pertenece, en las tierras bajas, él, el judío, iba y venía. (Celan, 1983c, p.169, 1996, p.15)

¿A qué se refiere Celan cuando dice que "el sol, y no sólo él, se había hundido en el ocaso (untergegangen)"? El verbo alemán untergehen, clave para la comprensión de "Gespräch im Gebirg", quiere decir literalmente "caminar (gehen) hacia abajo (unter)", esto es, "descender", "bajar", pero también se refiere al "atardecer", al "caer" o "hundirse" del sol en el "crepúsculo". El sustantivo Untergang tiene, por su parte, el significado de "ocaso", "hundimiento", "destrucción", "decadencia", como en el título de la famosa obra Oswald Spengler, Der Untergang des A bendlandes. Tomando deliberadamente la palabra untergehen en el doble sentido de "descender" y "andar cabeza abajo" (auf dem Kopf gehen), Celan alude explícitamente a Lenz, la novela inconclusa de Georg Büchner, que narra el triste destino de Jakob Michael Lenz, poeta del Sturm und Drang y contemporáneo de Goethe. En "Der M eridian", Celan citará el comienzo de esta novela: "El 20 de enero iba andando Lenz por la montaña ... No sentía ningún cansancio, pero a veces le resultaba fastidioso no poder andar cabeza abajo" (Celan, 1983c, p.193-4; Büchner, 1988, p.117). Por otro lado, este primer párrafo evoca también a Nietzsche, que en la soledad de Sils-M aria concibió A lso sprach Zarathustra como A dorno recordaría en un famoso ensayo de sus Noten zur Literatur (Adorno, 1977, p.326-9). En la dedicatoria de un ejemplar de "Gespräch im Gebirg", Celan escribió: "En memoria de Sils-M aria y de Friedrich Nietzsche, que - como sabes - hubiera querido matar a todos los antisemitas" (Felstiner, 1995, p.140). Según Pöggeler, Celan subrayó también en el Nietzsche de Martin Heidegger una frase de Zaratustra, que concuerda con la que da inicio a su propio texto: "Pues no sólo un sol se había hundido en el ocaso 
(untergegangenen) para mí" (Pöggeler, 1980, p.238). Cabe notar que Heidegger trascribe esta frase al comentar el capítulo "Vom Gesicht und Rätsel" de Also sprach Zarathustra (Heidegger, 1961, p.262), donde se expone la experiencia del "eterno retorno", pero omite las líneas que la preceden: "Sombrío caminaba yo hace poco a través del crepúsculo de color de cadáver - sombrío y duro, con los labios apretados" (Nietzsche, 1988, p.198).

¿Por qué Celan elige este "crepúsculo de color de cadáver" como escenario del diálogo entre Klein y Groß, entre el poeta y el filósofo judíos? En 1949, Adorno había expresado en su ensayo "Kultur und Gesellschaft", recogido posteriormente en Prismen (1955): "Después de Auschwitz, escribir un poema es barbárico, y este hecho corroe incluso el pensamiento que afirma por qué hoy se ha vuelto imposible escribir poesía" (Adorno, 1977, p.30). Aunque la prensa alemana utilizó a menudo esta frase para descalificar "Todesfuge", Adorno no podía conocer entonces el poema de Celan, que recién tuvo difusión a partir de 1952, cuando la editorial Fischer publicó Mohn und Gedächtnis. ${ }^{3}$ Por lo demás, teniendo en cuenta el contexto en que fue hecha esta afirmación, cabe pensar que se trataba menos de un diagnóstico contrario a la poesía que de una réplica velada a Heidegger, cuyo giro hacia la palabra ungida de Friedrich Hölderlin enmascararía, desde la perspectiva de Adorno, la tentativa de disolver una historicidad política que se concretó en el horror nazi. ${ }^{4}$ En 1962, trece años más tarde de aquella polémica aseveración, declaró por Radio Bremen: "No quisiera atenuar la frase según la cual, después de Auschwitz, seguir escribiendo lírica es barbárico" (A dorno, 1974, p.422). Sin embargo, en el capítulo final de Negative Dialektik (1966), titulado precisamente "Nach Auschwitz", Adorno volvería sobre su formulación para rectificarla:

Cuando en el campo de concentración los sádicos anunciaban a sus víctimas: "mañana vas a serpentear (schlängeln) hasta el cielo como el humo de esa chimenea", eran exponentes de la indiferencia por la vida individual a que tiende

3 Celan fechaba la composición de "Todesfuge" en 1945. Una primera versión del poema, traducida al rumano por Petre Solomon en la revista Contemporanul, hacia 1947. Resulta del todo improbable que Adorno haya tenido acceso a la edición de Der Sand aus der Urnen (Viena, A. Sexl, 1952), retirada de inmediato de circulación por Celan a causa de las numerosas erratas. Sobre los ataques de la prensa alemana a Celan, ver Felstiner, 1995, p.148-9, 223-7 y 320-1.

4 Conviene recordar aquí que Celan se reunió con Heidegger en la Selva Negra el 25 de julio de 1967, de lo que da cuenta su poema "Todnauberg", publicado primero como originalmente como plaquette en 1968 y luego incluido en Lichtzwang (Celan, 1983b, p.255-6). Sobre este punto, ver Otto Pöggeler, 1989, p.259-71 y Pierre J oris, 1988. 
la historia ... Nada puede sacar [al individuo] de ese espanto, como tampoco pudo hacerlo de la alambrada electrificada que rodeaba el campo de concentración. La perpetuación del sufrimiento tiene tanto derecho a expresarse como el torturado a gritar; tal vez por eso haya sido falso decir que, después de Auschwitz, ya no es posible escribir poemas. (Adorno, 1973, p.362)

Adorno escribió esto después de conocer los poemas de Celan. Es inevitable oír en los términos de su retractación el eco de los siguientes versos de "Todesfuge":

Ein Mann wohnt im Haus der spielt mit den Schlangen der schreibt er schreibt wenn es dunkelt nach Deutschland dein goldenes Haar Margarete er schreibt es un tritt vor das Haus und es blitzen die Sterne er pfeift seine Rüden herbei

er pfeift seine J uden hervor läßt schaufeln ein Grab in der Erde er befiehlt uns spielt auf nun zum Tanz

Ein Mann wohnt im Haus der spielt mit den Schlangen der schreibt der schreibt wenn es dunkelt nach Deutschland dein goldenes Haar Margarete dein aschenes Haar Sulamith wir schlaufen ein Grab in den Lüften da liegt man nicht eng

Er ruft spielt süsser den Tod der Tod ist ein Meister aus Deutschland er ruft streicht dunkler die Geigen dann steigt ihr als Rauch in die Luft dann habt ihr ein Grab in den Wolken da liegt man nicht eng. (Celan, 1983a, p.41)

Un hombre vive en la casa juega con las serpientes escribe escribe al anochecer a Alemania tu cabello de oro Margarita lo escribe y sale de la casa y relampaguean las estrellas silba a sus perros aquí silba a sus judíos acá manda cavar una tumba en la tierra nos ordena ahora toquen música de baile

Un hombre vive en la casa juega con las serpientes escribe escribe al anochecer a Alemania tu cabello de oro Margarita tu cabello de ceniza Sulamita cavamos una tumba en el aire allí no hay estrechez

Grita toquen más dulce a la muerte la muerte es un maestro de Alemania grita tañan más sombríos los violines luego ascenderán como humo en el aire luego tendrán una tumba en las nubes allí no hay estrechez. (Celan, 1996, p.16)

El sádico que en el texto de Adorno amenaza a su víctima, diciéndole "mañana vas a serpentear hasta el cielo como el humo de la chimenea", ¿no es el hombre de ojos azules que en el poema de Celan "juega con las serpientes", "escribe al anochecer a A lemania" y manda a los judíos cavar "una tumba en el aire"? ¿No es el mismo que azuza a los perros, hace 
formar a los prisioneros y, echando mano de la pistola que lleva al cinto, ordena a unos hincar profundamente sus palas en la tierra para abrir una fosa, mientras la orquesta del campo ejecuta ese "tango de la muerte", ese Tangoulmortii del que hablaba el título original del poema, ese Todestango cuya melodía no era sino la del tango "Plegaria", compuesto por el argentino Eduardo Bianco, que en 1940 tocó para Hitler y Goebbels. ${ }^{5} \mathrm{El}$ reconocimiento de Adorno fue ciertamente mucho más allá de estas líneas de Negative Dialektik. En 1963, luego de leer "Gespräch im Gebirg", dedicó a Celan su ensayo "Valérys Abweichungen", incluido en Noten zur Literatur (Adorno,1974, p.158) y proyectó escribir un trabajo sobre su obra, para el cual tomó numerosos apuntes en su propio ejemplar de Sprachgitter. Si bien - acaso para pesar de Celan - el texto de Adorno nunca llegó a ver la luz, en los paralipómenos de Ästhetische Theorie (1970), se encuentra un importante señalamiento, válido sobre todo para sus poemas de madurez:

En el representante más significativo de la poesía hermética de la lírica alemana contemporánea, Paul Celan, se ha invertido el contenido de lo hermético. Esta lírica se ha abierto paso entre el pudor del arte en vistas del sufrimiento sustraído tanto de la experiencia como de la sublimación. Los poemas de Celan nombran un indecible horror a través del silencio. Transforman su verdadero contenido en una cualidad negativa. Emulan un lenguaje que está desamparadamente por debajo de la vida humana, aun por debajo de la vida orgánica como tal: el lenguaje de las cosas muertas, de las piedras y de las estrellas. Los últimos rudimentos de la materia orgánica son eliminados de ellos, de manera tal que sobreviene eso que Benjamin descubrió en Baudelaire: una lírica sin aura. (Adorno, 1970, p.447).

Importa retener esta observación. Los poemas de Celan no dicen el silencio: nombran "un indecible horror a través del silencio". No hablan de la muerte, ni discurren sobre ella: no le cantan impúdicamente, como el hombre que en "Todesfuge" juega con las serpientes. Pues esa muerte viril (der Tod ), que es un "maestro de Alemania", en el doble sentido de "amo" y de "clásico", ¿no escribe acaso poemas, al igual que Celan, en la lengua de Goethe? Los poemas de Celan, parece sugerir Adorno, no marchan hacia la muerte: proceden, se abren paso a través de ella, la atraviesan. "Nadie/ testifica por/ el testigo", dice un poema de Atemwende (Celan, 1983b, p.296): hablando desde ese "después de Auschwitz" que

5 Ver al respecto la abundante documentación aportada en Felstiner (1995, p.22-41), donde entre cosas se informa que el "tango de la muerte" fue grabado por A leksander Kulisiewicz en Songs from the Depth of Hell, Folkways FS37700. 
problematiza Adorno, desde el interior mismo de la Shoa, Celan es ese testigo "por" (für) el cual nadie testifica, "en lugar de" y "en favor de quien" nadie puede dar testimonio (Derrida, 1996, p.19). Judío sobreviviente de los campos, Celan no tiene otra alternativa que escribir en esa lengua alemana que es, a la vez, su lengua materna (M uttersprache), la lengua de su madre y de sus verdugos. En esta experiencia fundamental radica su "lírica sin aura": si la poesía de Celan alcanza un tono sublime, no es porque detente una palabra oracular, mensajera de los dioses, una palabra purificada y ascendida como la de Hölderlin, sino porque su palabra es una palabra que camina junto a las palabras, "una palabra a imagen del silencio" (Celan, 1983a, p.92): "Una palabra - ya sabes:/ Un cadáver" (Celan, 1983a, p.125).

"Madre, ellos escriben poemas", repite Celan en "Wolfsbohne". ¿Cuál es la verdad terrible que viene a mostrar este verso? Si después de Auschwitz no es posible escribir poesía, como ha llegado a sostener Adorno, ¿es porque en Auschwitz había poesía? ¿Qué significa afirmar que en Auschwitz el poeta era, al mismo tiempo, el verdugo? La jerga del sádico que amenaza a su víctima diciéndole "mañana vas a serpentear hasta el cielo como el humo de la chimenea", ¿no se vale acaso de "metáforas", no es también un "lenguaje poético"? ${ }^{6}$ En "Todesfuge" se lee: "der Tod ist ein Meister aus Deuchtland sein Auge ist blau/ er trifft dich mit bleierner Kugel er trifft dich genau" (p.42)?¿ Qué sugiere esta rima la única rima final consonante de todo el poema - entre el ojo "azul" (blau) del verdugo y su disparo "certero" (genau)? La poesía en Auschwitz - parece insinuar Celan - tenía la contundencia material de una "bala de plomo", un grado de precisión equivalente al registro burocrático de los prisioneros en el archivo del campo, una exactitud cuanto menos comparable al número que sobre la piel les marcaban a fuego.

¿Podría suponerse, entonces, que la poesía de Celan - y con ella toda la poesía alemana después de Auschwitz - es la continuación del poema que se origina en el verdugo? ¿Poesía de sobrevivientes, de víctimas despojadas incluso del derecho a una lengua en la que poder expresarse, condenadas a la "perpetuación del sufrimiento" en un grito que se petrifica en la lengua de sus victimarios? Celan reclama en "Wolfsbohne" una respuesta de su madre muerta. Fue ella, que prefirió el alemán al rumano,

6 Sobre el problema de la metáfora en Celan, ver la comunicación de Martine Broda (1992), donde la autora polemiza con la afirmación de Ferenc Feher y Agnès Heller "'La poésie après l'holocauste", en Lettre Internationale, $\mathrm{n} .26$ ) en el sentido de que escribir "poesía sobre Auschwitz" sería "hacer metáforas sobre una metáfora". 
la que lo llevó con sus palabras a Alemania, la que le enseñó a hablar su lengua en la Bukovina a través de refranes, cuentos de hadas y canciones, como aquella que evoca en Die Niemandsrose: "la canción del abejorro que resplandece maternal, estivalmente, en-/ sangrentada al borde/ de toda escabrosa/ sílaba/ resistente al frío invernal" (p.290). Fue su madre judía la que le dio la lengua alemana y lo inició al mismo tiempo en la poesía, sin saber que estaba alimentando así a los asesinos. ¿Alimentándolos? "Madre, iqué/ tierra más extraña produce tu fruto!", escribe Celan. "¡Produce tu fruto y alimenta/ a los que matan!”. ¿Cuál es la semilla que genera tanto odio? ¿En qué consiste esa "simiente de lobo"?

Víctimas y verdugos se nutren de lo mismo: la lengua alemana. Celan - en su condición de poeta, sobreviviente y judío - es fruto de su Muttersprache, cuyo suelo "extraño" abona a la vez con sus versos: "Madre, ellos escriben poemas./ Madre, ellos no los escribirían,/ si no fuera por el poema que/ yo escribí por/ tu voluntad, por/ voluntad de tu/ Dios." Los judíos - parece querer decir Celan - son quienes alimentan en tierra extranjera, en la "más extranjera de las tierras" (fremdester Acker), la "simiente de lobo": ellos - la madre, el poeta y su hijo - fecundan con sus palabras a quienes luego serán sus verdugos. ¿Por voluntad del Dios judío? "Loado, decías, sea/ el eterno y/ agradecido, tres/ veces/ Amén." De ser así, se trataría de un círculo, como el que traza la propia estructura de "Wolfsbohne", que se abre y se cierra con la misma estrofa: "Echa el cerrojo: Están/ las rosas en casa./ Están/ las siete rosas en casa. Está/ el candelabro de siete rosas en casa./ Nuestro/ hijo/ lo sabe/ y duerme." ¿Qué cosa sabe el niño? El niño, al igual que Celan, sabe aquello que la madre del poeta ignora, porque ha muerto en Aussig, a orillas del Elba: que nada redime. "Madre, estoy/ perdido", dice Celan. "Madre, estamos perdidos." En "Psalm", poema de Die Niemandsrose que adquiere una nueva dimensión a la luz de "Wolfsbohne", se lee:

Niemand knetet uns wieder aus Erde und Lehm,

Niemand bespricht unsern Staub.

Niemand.

Gelobt seist du, Niemand.

Dir zulieb wollen

wir blühn.

Dir

entgegen.
Nadie nos volverá a amasar con tierra y barro.

Nadie inspirará nuestro polvo.

Nadie.

Loado seas, Nadie.

Por amor a ti queremos

florecer.

A ti

enfrentados. 
Ein Nichts

waren wir, sind wir, werden

wir bleiben, blühend:

die Nichts-, die

Niemandsrose.

Mit

dem Griffel seelenhell,

dem Staubfaden himmelw üst,

der Krone rot

von Purpurwort, das wir sangen

über, o über

dem Dorn.
Una Nada

fuimos, somos, seremos

siempre, floreciendo:

de Nada, la

rosa de Nadie.

Con

nuestro pistilo resplandeciente de almas, con la hebra de polvo yerma del cielo, con la roja corona

de la palabra púrpura que entonábamos sobre, oh sobre

el trono. (Celan, 1983a, p.225)

En un ensayo aparecido el 15/16 de julio de 1967 en las páginas del Süddeutschen Zeitung, Adorno (1974, p.603) reflexionaba: “La frase según la cual, después de Auschwitz, ya no está permitido escribir poesía, no da en el blanco, pero por cierto, puesto que era posible y continúa siéndolo hasta en lo incalculado, ya no puede concebirse un arte divertido". Lo "divertido" (heiter) no es aquí simplemente lo "jocoso", en oposición a lo "serio": designa, sobre todo, aquello que en la industria cultural se presenta como bálsamo, generalmente bajo la forma del entretenimiento. Es la poesía como decir eufónico, que pretende plasmar bellamente aun los acontecimientos más horribles, lo que Adorno parece poner en entredicho. ¿En qué medida, por ejemplo, un poema como "Todesfuge" no eleva al más alto nivel del arte los hechos espantosos que describe y que lo generaron? ¿No cabe sospechar de la notoriedad que alcanzó en la A lemania de posguerra, donde no sólo era estudiado en las escuelas como una "fuga de Bach" - tema, contratema, motivo, repetición, variación, coda - sino también interpretado en términos de "perdón y reconciliación" (Felstiner, 1995, p.118)? Celan era plenamente consciente de la paradójica recepción de su poema y, en los últimos años de su vida, se negó sistemáticamente a leerlo en público, llegando incluso a prohibir su reedición en antologías populares. ¿Hasta dónde la poesía, si no se quiere renunciar a ella, puede en efecto seguir siendo, después de Auschwitz, gobernada por la retórica literaria? ¿Es el vínculo entre arte y poesía por sí mismo evidente? ¿Qué pasaría si la respuesta a la pregunta por la poesía no fuera lo "poético", ni el "poetizar" de una experiencia originaria, ni el "Poema" en tanto objeto autosubsistente? Como "arte de la palabra", sugiere Celan en "Der Meridian", la poesía es una "conversación" (Unterhaltung), que "podría no llegar a tener fin si algo no se interpusiera" (Celan 1983c, p.187). "Pero algo se interpone", agrega Celan. 
¿Qué es lo que viene a interponerse (dazw ischenkommen) en una entretenida charla sobre arte? ¿Qué cosa viene, de pronto, a interrumpir la conversación, a interferir en ella, a generar confusión y malestar entre los interlocutores? ¿Qué es esto que viene a detener el flujo natural de las palabras, a provocar un malentendido, un ruido, un desvío, en fin, un cambio de rumbo? La "conversación" a la que alude Celan se encuentra en la tercera escena del Acto II de Dantons Tod, el único drama que Büchner publicó en vida. Allí el arte es comparado con la mitológica estatua de Pigmalión, "criatura estéril", semejante a una "marioneta" que deja ver los hilos que la mueven, a un muñeco de madera y trapo cuyas articulaciones estallan en "cinco pies yámbicos" (Celan, 1983c, p.187, Büchner, 1988, p.61). Celan cita también Woyzeck, donde el arte ya no es objeto de una conversación privada sobre la creación "espléndida", "rutilante" y "luminosa", sino que es exhibido en público por un "charlatán de feria", junto a la "criatura" y el "genio acuático", bajo la "forma de un mono" amaestrado, vestido "con chaqueta y pantalón" y un "sable" en la mano (Celan, 1983 c, p.187, Büchner, 1988, p.198). Una tercera definición del arte es tomada por Celan de la escena final de la comedia Leonce und Lena, donde Valerio, el bufón de la corte, presenta ante el rey Pedro a la pareja de enamorados disfrazada de autómatas: "Nada más que arte y mecanismo - dice Valerio -, nada más que planchas de cartón y cuadrantes de reloj" (Celan, 1983c, p.188; Büchner, 1988, p.187). Por último, Celan encuentra en Lenz una cuarta imagen para el arte: una "cabeza de Medusa" que convierte en piedra todo aquello que es natural, todo aquello que es vida y estremecimiento (Celan, 1983c, p.188, Büchner, 1988, p.128).

Una marioneta, un autómata, un mono: ¿es esto el arte? Un charlatán de feria, un bufón, una cabeza de M edusa: ¿es esto el poeta? Dejo, por el momento, sin responder estas preguntas y vuelvo sobre aquello que se "interpone" en la charla que mantienen Danton y sus seguidores en el drama de Büchner. La escena, como subraya Celan, tiene lugar en un cuarto, lejos de la Conserjería de Luxemburgo, la antesala de la guillotina. En efecto, el arte es - en toda época y lugar también un tema de conversación, es decir, un "problema" sobre el que "puede hablarse mucho" (Celan, 1983c, p.188), pero cuya esencia ciertamente no se vislumbra desde la inminencia de la muerte. El arte comienza a más de un paso del cuerpo: únicamente allí, a resguardo del peligro, se abre esa distancia contemplativa - que Benjamin llamaba "aura" - sin la cual no es posible una experiencia estética. No por otro motivo, el hecho de que en Dantons Tod los revolucionarios, sentencia- 
dos a muerte, continúen discutiendo sobre arte en la Conserjería prepara dramáticamente el terreno para la irrupción de esa figura que todo el tiempo ha estado escuchando a los conspiradores, aparentemente sin comprender.

Aquello que se "interpone" en la conversación - dice Celan - "procede sin consideración, llega con nosotros a la Plaza de la Revolución" (p.189). Las breves indicaciones de Büchner en el Acto IV enmarcan la escena con deliberado patetismo: "Los carros vienen atropellando y se detienen delante de la guillotina. Hombres y mujeres cantan y bailan la Caramañola. Los condenados entonan la Marsellesa." (Büchner, 1988, p.111). Allí están Danton, su fiel amigo Camille Desmoulins, periodista y diputado de la Convención, y los demás hombres que fueron decisivos en los primeras jornadas de la Revolución Francesa. Todos se preparan a morir "una muerte teatral" (Celan, 1983c, p.189). Sobre la tribuna - que es también un "patíbulo" - tienen todavía "palabras artificiosas" (kunstreiche Worte) para decir, discursos grandilocuentes, frases hechas del estilo "marchemos todos juntos a la muerte". Fabre d'Eglantine, convencional dantonista, declara incluso que "podría morir 'dos veces'". El público se exalta. La escena exhibe el paroxismo, la embriaguez revolucionaria que toma conciencia de sí en el espectáculo de la muerte, en los cuerpos mutilados que se apilan al pie de la guillotina. Se trata de la "libertad universal" de la que habla Hegel en la Phänomenologie des Geistes, que no puede presentarse de otro modo que como "facción", que se complace en el "obrar negativo" y la "furia del desaparecer": el "terror" que se reconoce en "la muerte más fría y más banal, sin otra significación que la de cortar una cabeza de col o beber un sorbo de agua" (Hegel, 1964, p.449-59).

Ya no hay muertes bellas dadas en sacrificio. Los crímenes forman parte del orden del día. Lo que queda es una rutina mortal, impersonal y calculada: la muerte administrada burocráticamente. "Sólo un par de voces, 'algunas' anónimas 'voces' - remarca Celan - encuentran todo trillado y aburrido" (Celan 1983c, p. 189). Sin embargo, allí donde la muerte se reduce a espectáculo y mecanismo de relojería, donde "pathos y sentencia" confirman el triunfo de la marioneta, del autómata y el mono con sable de militar, todavía es posible la poesía: "Allí todavía está Lucile, la ciega al arte, la misma Lucile para la que la lengua es algo personificable y perceptible, allí todavía está Lucile con su repentino ¡Viva el rey!. " Frente a todos los discursos pronunciados desde la tribuna, esta frase dice Celan - es una "contrapalabra" (Gegenwort): una palabra que "rompe el alambre", que "ya no se prosterna ante los guardias y caballos de 
desfile de la historia" (p.190). En este ¡Viva el rey! no se exalta ninguna monarquía ni pasado alguno a conservar: "Lo que se celebra es la majestad del absurdo que da testimonio del presente de la humanidad". Constituye un "acto de libertad", una afirmación del individuo, que al dar su palabra se sustrae al mecanismo impersonal de la guillotina, que al condenarse se niega a morir una muerte ajena, que con su grito desesperado se resiste a que se le arrebate una muerte que le es propia.

En efecto, a la pregunta por el arte cabe ponerle acentos distintos: “... el agudo del hoy, el grave de la historia - también de la historia de la literatura -, el circunflejo, un signo de expansión en lo eterno" (Ibidem). Celan elige el "acento agudo" para hablar no sólo de la posibilidad, sino también de la necesidad y del significado que tiene, después de Auschwitz, el acto mismo de escribir poesía. "Oficio es algo que se hace con las manos ... No veo ninguna diferencia de principio entre una trompada y un poema", escribe a Hans Bender en 1960 (p.177). "He aquí el poema - comenta Emmanuel Levinas: lenguaje acabado, reducido a una interjección, a una expresión tan poco articulada como un guiño, como un signo ofrecido al prójimo ... Comunicación elemental y sin revelación, infancia balbuceante del discurso, torpe inserción en la famosa lengua que habla, en el famoso Sprache spricht, entrada del mendigo en la morada del ser" (Levinas, 1976, p.53-4). La poesía de Celan se sitúa ciertamente en un nivel "pre-sintáctico" y "pre-lógico", pero también en un nivel "pre-ontológico": en una proximidad táctil que busca restablecer un contacto originario con el otro. Es en este sentido que debe entenderse la frase: "El poema es un diálogo, a menudo un diálogo desesperado" (Celan, 1983c, p.198). El término Gespräch, que aquí se vierte como "diálogo", se opone en el contexto de "Der Meridian" a Unterhaltung (conversación) como la comunicación auténtica a la inauténtica. El poema se halla, desde su origen, "librado al secreto del encuentro" (im Geheimnis der Begegnung): “... tiende hacia un otro, necesita de ese otro, necesita alguien enfrente. Lo busca, le responde" (Ibidem). Este encuentro que persigue el poema se funda en la "atención" (Aufmerksamkeit) que dedica a su providencial destinatario, a aquel al que está esencialmente dirigido como un "mensaje en una botella" (p.186): la atención en virtud de la cual se abre una luminosidad, un espacio "dialógico" en el que el Yo se constituye como un Tú, en el que el que el íntimo y desconocido Yo "... es el Tú del poema, completamente real" (Gadamer, 1997, p.126). Dicho de otra manera, la utopía del poema es el otro: "no es el sueño y el destino de una errancia maldita, sino el claro donde el hombre se muestra" (Levinas, 1976, p.52). 
La tierra prometida del poema es un otro, pero también lo otro, lo otro "en su completa otredad" (Celan, 1983c, p.196). En "Und mit dem Buch aus Tarussa", incluido en Die Niemandsrose, Celan hace suya la frase de Marina Tsvetaieva: "Todos los poetas son idisch" (Celan, 1983a, p.287), lo cual no significa sino que la poesía se escribe siempre en una lengua extranjera. En tanto extrañamiento de la lengua, tiene lugar allí donde alguien "corta a los asesinos la palabra", donde un Yo - libre de pronto como Lucile - hace saltar el continuum de la lengua, desvía momentáneamente su curso "natural", le imprime con su propia voz un giro, un cambio de dirección. Por eso puede decirse que, para Celan, "la poesía es interrupción de la lengua" (Lacoue-Labarthe, 1994, p.132). Lo barbárico, después de Auschwitz, sería abandonarse a la cadencia eufónica de las palabras, a la autorreferencialidad del discurso poético, a la proliferación del lenguaje como mero significante. Ya en 1958, al contestar a una encuesta de La Librairie Française et Étrangère Flinker, Celan explicaba:

La poesía alemana ha seguido, creo yo, un camino distinto que la francesa. Con los acontecimientos más tenebrosos en su memoria y los más dudosos a su alrededor, ya no puede, teniendo presente la tradición en la que se encuentra, hablar más el lenguaje que muchos oídos preparados hoy parecen seguir esperando de ella. Su lenguaje se ha vuelto más sobrio, más fáctico, desconfía de la "belleza, trata de ser verdadero. Lo que significa que puedo, en el plano visual, conservando la policromía de la actualidad que aparece ante los ojos, ir en busca de una palabra, de un lenguaje "más gris", de un lenguaje cuya "musicalidad" ya no tiene nada en común con aquella "eufonía" que, más o menos despreocupada, baila todavía al compás de los acontecimientos más espantosos.

Este lenguaje, con toda su indiscutible polivalencia expresiva, tiende a la precisión. No transfigura, no "poetiza", nombra y sitúa, intenta medir el campo de lo dado y de lo posible. Decididamente, no se trata del lenguaje en sí mismo, del mero lenguaje en producción, sino siempre de un Yo que habla desde el particular ángulo de inclinación de su propia existencia, preocupado por el entorno y la orientación. La realidad no existe, la realidad debe ser buscada y conquistada (Celan, 1983c, p.167, 1996, p.24).

En “Der M eridian", asociando la figura de Lucile a la de Lenz, Celan dice: "Quien tiene el arte delante de sus ojos y espíritu ... se olvida de sí mismo. El arte crea una lejanía del Yo (Celan, 1983c, p.193). ¿Quiere decir entonces que, después de Auschwitz, la poesía debe devenir "antiarte", según la dialéctica del arte contra el arte acuñada por Adorno? Celan parece señalar más bien otra cosa. La esencia de la poesía no se determina por el arte, sino a la inversa: no es la poesía la que debe 
transitar el camino del arte, expandiendo sus límites más allá de sí mismo, sino el arte el que debe seguir el "camino de regreso abierto por la poesía" (p.194). La poética de Celan se inscribe sólo de manera mediata en la experimentación, el trabajo de la elipsis y la tendencia al enmudecimiento. Sobre todo, se mueve en los bordes del poema, entre su "ya no" (Schonnicht-mehr) y su "todavía" (Immer-noch), entre lo que la poesía ya no es más y lo que continuará siendo siempre: no palabra ascendida o metafórica, aunque presumiblemente tampoco lenguaje antipoético, sino "lenguaje pleno", puesto en libertad dentro del contexto no-poético de su tiempo, lenguaje configurado "por quien no olvida el ángulo de inclinación de su propia existencia" y que es, según su esencia más íntima, "presente y presencia simultáneamente (Gegenwart und Präsenz)" (Celan, 1983c, p.197-198). Por supuesto, "el poema absoluto no existe", pero en cada poema verdadero, en el menos pretencioso, surge una demanda incontestable, una "pretensión inaudita" (Ibidem p.199). Parafraseando a Benjamin, a quien Celan cita expresamente en "Der M eridian", puede decirse que cada poema lleva consigo un "índice temporal que remite a la salvación", una "débil fuerza mesiánica" sobre la cual los seres humanos, como depositarios de una promesa irrenunciable de felicidad, "tienen un derecho" (Benjamin, 1974, p.694).

Este "índice temporal", este datum no es la fecha histórica, la circunstancia de la composición rubricada por el poeta al pie de sus versos, sino el schibboleth que constituye "la escritura poética de una lengua" (Derrida, 1994, p.36). Este schibboleth es una "bandera a media asta por hoy y por siempre" (Celan 1983a, p.131), una cicatriz y una contraseña, una marca en la piel, la estrella de la redención que relampaguea en el cielo: "Un trueno: la verdad misma que avanza/ entre los hombres/ en medio de un/ torbellino de metáforas" (Celan, 1983c, p.89). Para explicar en qué consiste este schibboleth, Celan vuelve a citar en "Der M eridian" el comienzo de Lenz: "El 20 de enero iba andando Lenz por la montaña ... No sentía ningún cansancio, pero a veces le resultaba fastidioso no poder andar cabeza abajo". Celan comenta: "El que anda cabeza abajo ... tiene el cielo como un abismo bajo sus pies" (p.195). Este abismo - esta "tumba en el aire" de la que habla "Todesfuge" - es el suelo del que brota literalmente la "oscuridad" de la poesía de Celan, una oscuridad que no se ornamenta de enunciados poéticos, sino que "reduce todos los tropos y metáforas ad absurdum" (p.199). Así es como Celan puede decir "cada poema lleva inscripto su 20 de enero" (p.196). El 20 de enero de 1942, reunidos en Wansee, Reinhardt Heydrich, Adolf Eichmann y otros doce jerarcas del Tercer Reich dispusieron ejecutar lo que llamaron "solución final". 
IBARLUCÍA, R. Seed of wolf: Celan, Adorno and poetry after Auschwitz. Trans/ Form/A ção (São Paulo), v.21-22, p.131-150, 1998-1999.

- ABSTRACT: From a posthumous poem by Paul Celan, this paper analyses Theodor W. Adorno's dictum about the impossibility of lyrical poetry after Auschwitz and try to define the influence of such proposition in Celan's work. At the same time, it inquires into the reception of Celan's poetry on Adorno's own ideas, especially on his Negative Dialektik and Ästhetische Theorie. Finally, it explores the paradoxes of every poetical language which pretend to express Holocaust artistically.

- KEYWORDS: Celan; Adorno; Auschwitz; poetry; language; art.

\section{Referências bibliográficas}

ADORNO, T. W. Gesammelte Schrifften 6. Edición de Gretel Adorno y Rolf Tiedemann. Francfort del Meno: Suhrkamp, 1973. . Gesammelte Scfrifften 7, 1970. . Gesammelte Scfrifften 10, 1977. . Gesammelte Scfrifften 11, 1996.

BENJ AM IN, W. Über den Begriff der Geschichte. In: BENJ AM IN, W. Gesammelte Schriften 1. Edición de Rolf Tiedemann y Hermann Schweppenhäuser. Francfort del Meno: Suhrkamp, 1974. p.691-704.

BRODA, M. Paul Celan, la politique d'un poète après Auschwitz. In: RANCIÈRE, J. (Comp.) La politique des poètes. París: Albin Michel, 1992. p.214-27.

BÜCHNER, G. Werke und Briefe. Edición de Franz J osef Görtz con un epílogo de Friedrich Dürrenmatt. Zurich: Diogenes, 1988.

CELAN, P. Gesammelte Werke 1. Edición de Beda Allemann y Stefan Reichert con la colaboración de Rolf Bücher. Francfort del Meno: Suhrkamp, 1983a. . Gesammelte Werke 2, 1983b.

. Gesammelte Werke 3, 1983c.

. Dossier Celan. Edición de Ricardo Ibarlucía. Diario de Poesía. (Buenos Aires), n.39, 1996.

. Die Gedichte aus dem Nachlass. Edición de Bertrand Badiou, J ean-

Claude Rambach y Barbara Wiedemann. Francfort del Meno: Suhrkamp, 1997a.

CELAN, P. Simiente de lobo. Traducción de R. Ibarlucía. Diario de Poesía, (Buenos Aires), n.43, 1997b. 
CLAUSSEN, D. Nach Auschwitz kein Gedicht? In: SCHWEPPENHÄUSER, G. WISCHKE, M. (Comp.) Impuls und negativität. Ethik und Ästhetik bei Adorno. Hamburgo: A rgument, 1995. p.44-51.

DERRIDA, J. Shibboleth for Paul Celan. In: FIORETOS, A. (Comp.) Wordtraces: readings of Paul Celan. Baltimore: The J ohns Hopkins Univerity Press, 1994. p.3-72.

- Hablar por el otro. Trad. de V. J oubert. Extracto de la conferencia Parler pour l'étranger (ou pour l'autre): témoignage et responsabilité: une lecture de Paul Celan, Buenos Aires, octubre de 1995. In: DOSSIER Celan, 1996, p.18-20.

FELSTINER, J. Paul Celan: Poet, Survivor, J ew. New Haven: Yale University Press, 1995.

GADAMER, H. G. Gadamer on Celan. "Who am I and Who are You?" and Other Essays. Trad. y edición de R. Heinemann y B. Krajewski. Con una introducción de Gerald L. Bruns. Nueva York: State University of New York Press, 1997.

HAM BURGER, M. Wolfsbohne. Times Literary Supplement, 16 mayo 1997.

HEGEL, G. W. F. Sämtliche Werke II. Hermann Glochner, 1927. Friedrich Frohmann, 1964. Frankfurt an Main: Suhrkamp, 4.ed. 1970.

HEIDEGGER, M. Nietzsche. Tubinga: Neske, 1961.

JORIS, P. Celan/Heidegger: translation at the mountain of death. In: POETIC THOUGHT \& TRANSLATION CONFERENCE, Wake Forest University, Oct. 1988.

LACOUE-LABARTHE, P. Catastrophe. In: FIORETOS, A. (Comp.) Wordtraces: readings of Paul Celan. Baltimore: The J ohn Hopkins University Press, 1994. p.130-46.

LEVINAS. Noms Propres. París: Fata M organa, 1976.

NIETZSCHE, F. Also sprach Zarathustra. In: COLLI, G. MONTINARI, M. (Ed.) Sämtliche Werke IV. Kritische Studien Ausgabe. Berlín: dtv/ Walter de Gruyter, 1988.

PÖGGELER, O. Kontroverses zur Ästhetik Paul Celans. Zeitschrift für Ästhetik und allgemeine Kunstwissenschaft, n.25 p.2, 1980. . Spur des Wortes. Friburgo: Karl Alber, 1989. 